\title{
Left Ventricular Herniation and Coronary Aneurysm
}

\author{
Kazuki Ito
}

Key words: left ventricular herniation, coronary aneurysm

(Intern Med 52: 927-928, 2013)

(DOI: 10.2169/internalmedicine.52.0014)

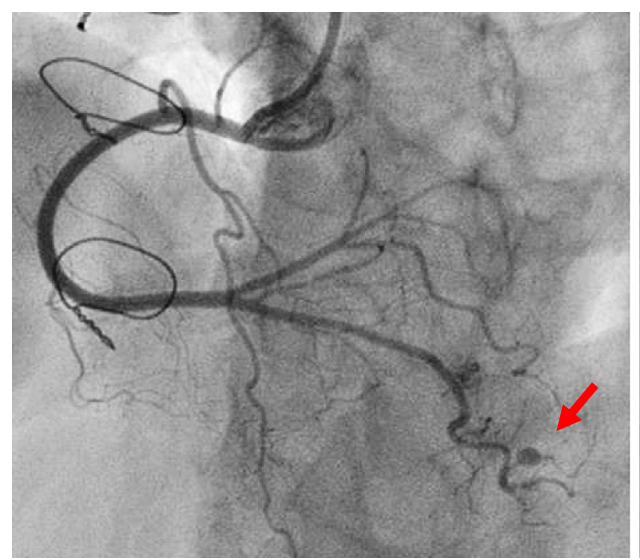

Right coronary artery

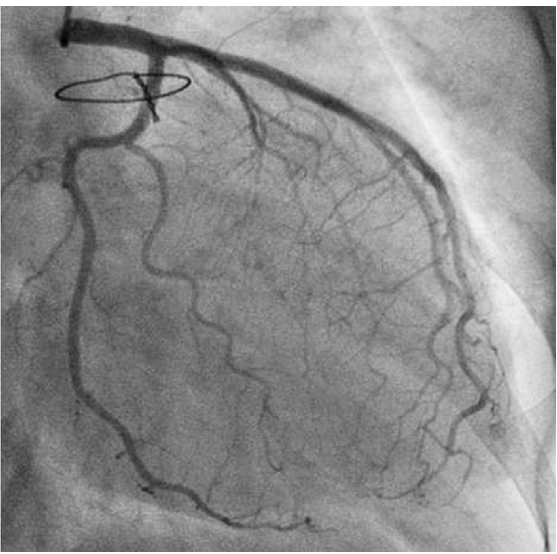

Left coronary artery

Picture 1.

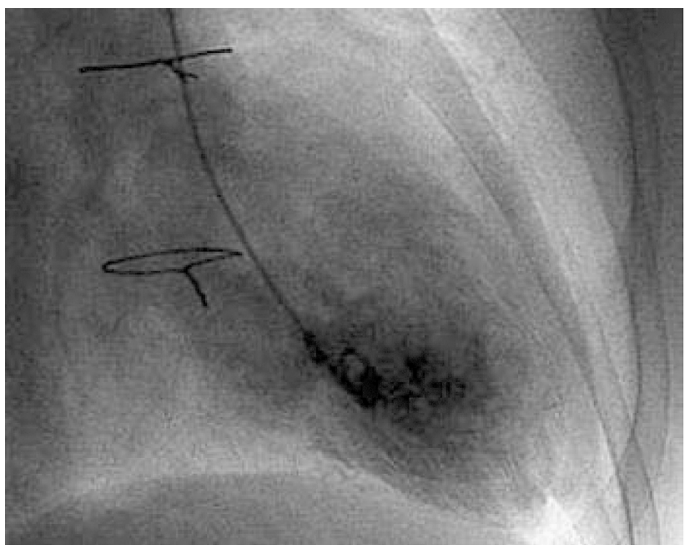

diastole

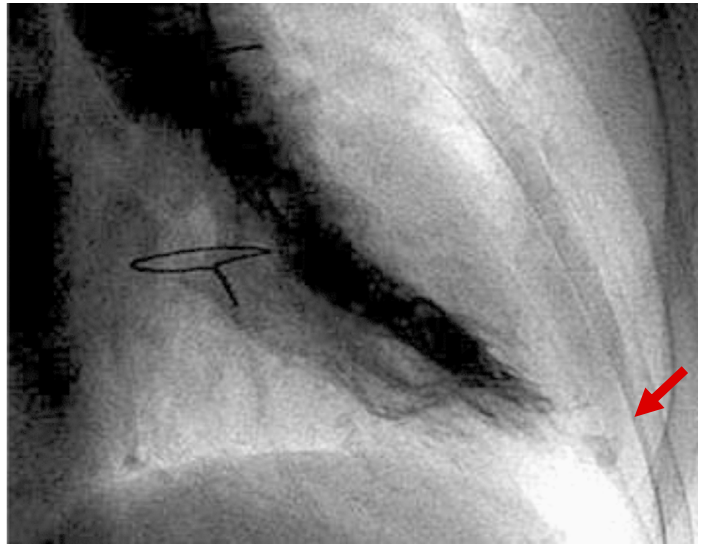

systole

Picture 2.

A 62-year-old woman was admitted to our hospital for an evaluation of chest pain at rest. She had undergone surgery for valvular heart disease at 16 years of age, although the details of the surgical management were unknown. Coronary angiography showed no stenotic lesions; however, it did reveal a solitary aneurysm in the distal portion of the right coronary artery (Picture 1). Left ventriculography disclosed a small aneurysm in the apex (Picture 2). Magnetic reso- 

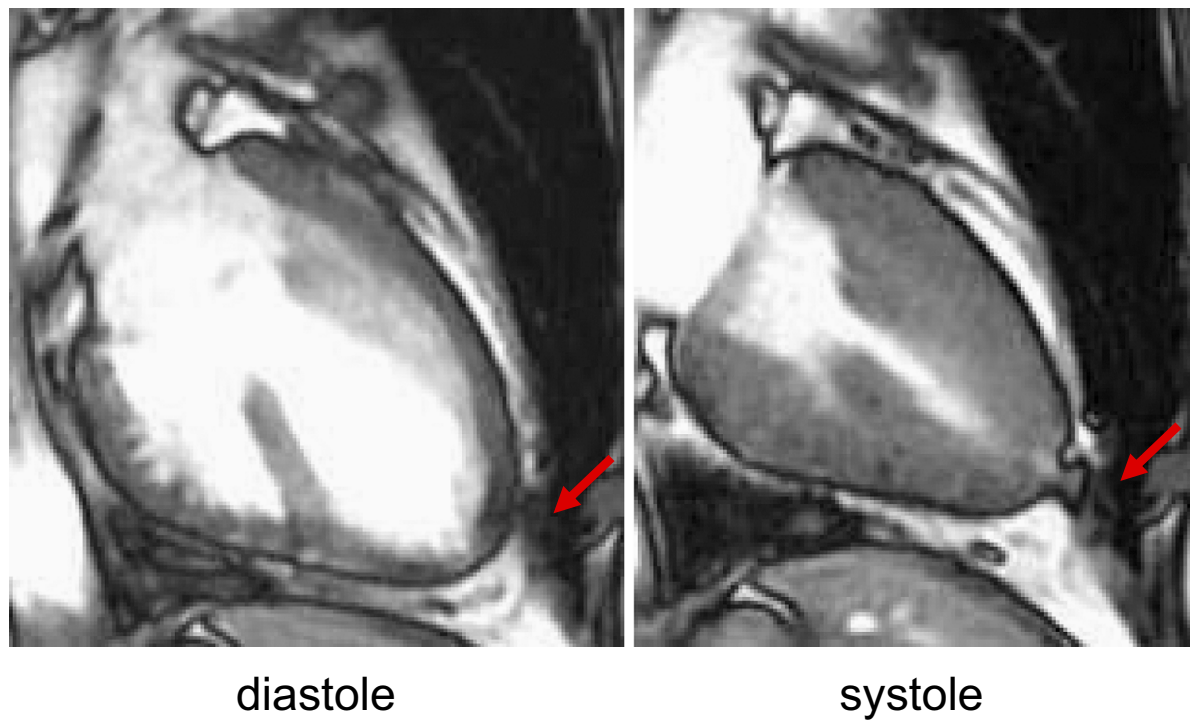

Picture 3.

nance imaging showed left ventricular herniation resulting from partial absence of the left pericardium (Picture 3). The hole in the left pericardium may have resulted from drainage during the surgical treatment. In addition, judging from the form of the coronary aneurysm and the patient's clinical history of chest pain, the coronary aneurysm might have been caused by spontaneous coronary dissection. In order to prevent any enlargement of the coronary aneurysm and ventricular herniation, the patient was placed on intensive antihypertensive therapy.

The author states that he has no Conflict of Interest (COI).

(C) 2013 The Japanese Society of Internal Medicine http://www.naika.or.jp/imonline/index.html 